\title{
Endoscopic management of eosinophilic esophagitis presenting as a double lumen esophagus
}

A 19-year-old man was referred to our unit with a 5-year history of dysphagia and food impaction. Upper endoscopy revealed a concentric stricture in the proximal esophagus, which underwent subsequent balloon dilation to $15 \mathrm{~mm}$. Strikingly, a well-established mucosal septum was identified below the stricture, forming a double-lumen esophagus (DLE) that partially obstructed the esophagus ( $\triangleright$ Fig. 1). Biopsies from the mid and distal esophagus revealed inflammation, and high dose proton pump inhibitors were started.

The patient continued to experience dysphagia and intervention was therefore planned (\Video 1). A gastroscope (GIFHQ290; Olympus, Tokyo, Japan) was introduced under general anesthetic. The proximal stricture was balloon dilated to $15 \mathrm{~mm}$. Indigo carmine dye was injected into the proximal end of the duplicate lumen to check patency as the dye flowed distally onto the main lumen. An SB-knife (Sumitomo Bakelite Co. Ltd., Tokyo, Japan) was used to divide the septum (ERBE VIO 200D, Endocut I, Effect 1, Duration 3, Interval 3; Erbe Elektromedizin $\mathrm{GmbH}$, Tübingen, Germany). The septectomy was performed from the proximal to the distal orifice without complications ( Fig.2). The patient's symptoms drastically improved after the procedure. Further biopsies were taken and confirmed eosinophilic esophagitis (EoE), and a 6-week course of fluticasone oral slurry was started. After 2 years of follow-up, he remains asymptomatic with no further interventions required ( Fig. 3).

EoE is a chronic immune condition presenting with symptoms of dysphagia or food impaction. Stricture development is the main indication for endoscopic treatment [1]. The DLE is a rare endoscopic finding, previously reported as a complication to nasogastric tube insertion [2] or associated with other uncom-

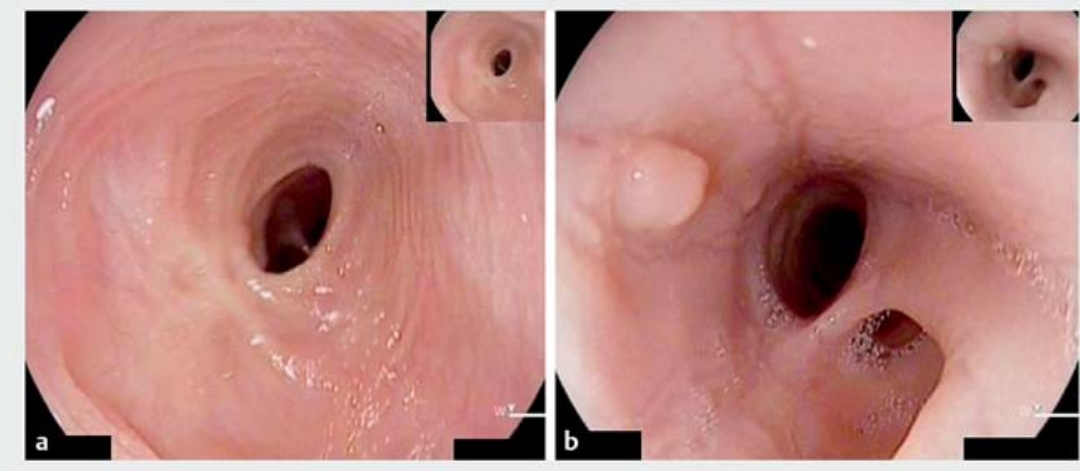

- Fig. 1 Baseline endoscopy findings. a Concentric stricture in the proximal esophagus, with ringed appearance of the esophagus. $\mathbf{b}$ Upper orifice of the double esophagus formed by a thick mucosal septum. See the typical linear furrows present in the eosinophilic esophagitis.
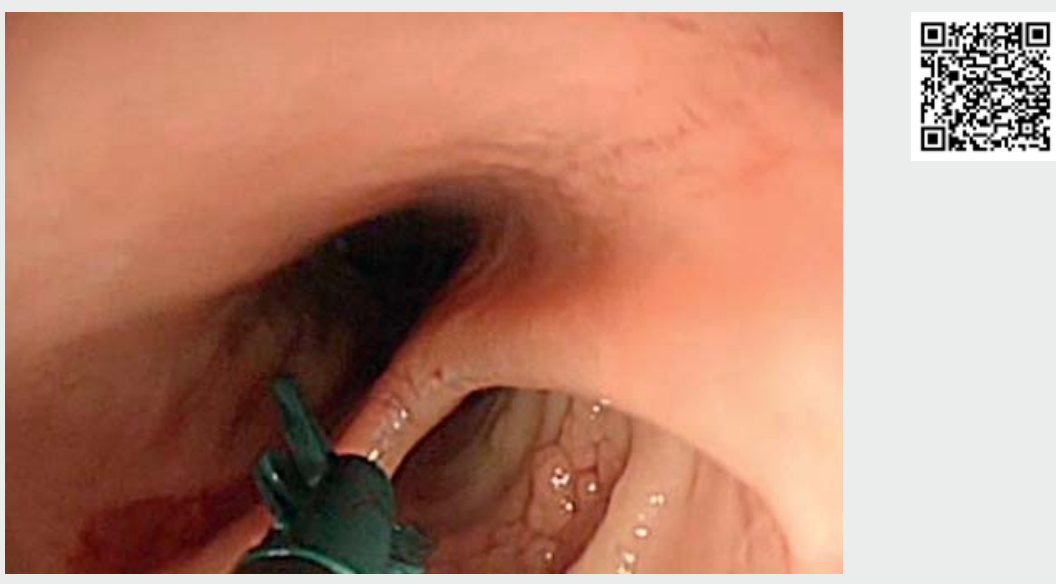

Video 1 Endoscopic treatment with septectomy for a double lumen esophagus as an unprecedented presentation of eosinophilic esophagitis.

mon conditions (i.e. esophagitis dissecans superficialis) [3]. To our knowledge, this is the first report of an EoE and DLE association and its successful management by endoscopic septectomy and balloon dilation.

Endoscopy_UCTN_Code_CCL_1AB_2AC_3AH

\section{Competing interests}

Krish Ragunath is a consultant for Olympus and has received research and educational grants from Olympus and Pentax. He received educational grant from ERBE. 

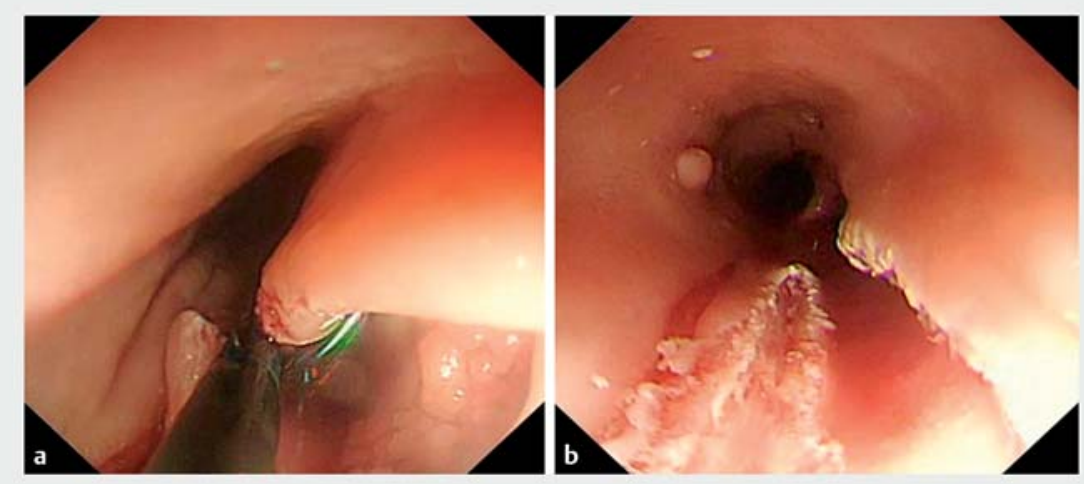

- Fig. 2 Septectomy. a An antegrade septectomy was performed starting at the proximal end. An SB-knife (Sumitomo Bakelite Co. Ltd., Tokyo, Japan) was chosen to carry out the procedure. $\mathbf{b}$ Final appearances of the esophagus.

The authors

Jose Santiago Garcia', John Duffy², Jacobo Ortiz-Fernandez-Sordo², Shivkumar Budihal'2, Adolfo Parra-Blanco ${ }^{2}$, Krish Ragunath ${ }^{2}$

1 Puerta de Hierro University Hospital of Majadahonda, Majadahonda, Spain

2 NIHR Nottingham Digestive Diseases Biomedical Research Centre, Nottingham University Hospitals NHS Trust, Nottingham, United Kingdom

\section{Corresponding author}

\section{Krish Ragunath, MD}

NIHR Nottingham Digestive Diseases Biomedical Research Centre, Nottingham University Hospitals NHS Trust, Queens Medical Centre Campus, E Floor, West Block, Derby Road, Nottingham, NG7 2UH, United Kingdom

Fax: +44-115-9691169

K.Ragunath@nottingham.ac.uk

\section{References}

[1] Hirano I, Moy N, Heckman MG et al. Endoscopic assessment of the oesophageal features of eosinophilic oesophagitis: validation of a novel classification and grading system. Gut 2013; 62: 489-495

[2] Le Mouel JP, Basile P, Gonzalez JM et al. Double lumen esophagus due to false submucosal path induced by nasogastric tube: endoscopic treatment with marsupialization. Endoscopy 2018; 50: E325-E326

[3] Patel AV, Dalal I. Endoscopic finding of a double lumen in the esophagus. Gastroenterology 2020; 158: 60-61

Bibliography

DOI https://doi.org/10.1055/a-1119-0894

Published online: 27.2.2020

Endoscopy 2020; 52: E316-E317

(c) Georg Thieme Verlag KG

Stuttgart · New York

ISSN 0013-726X

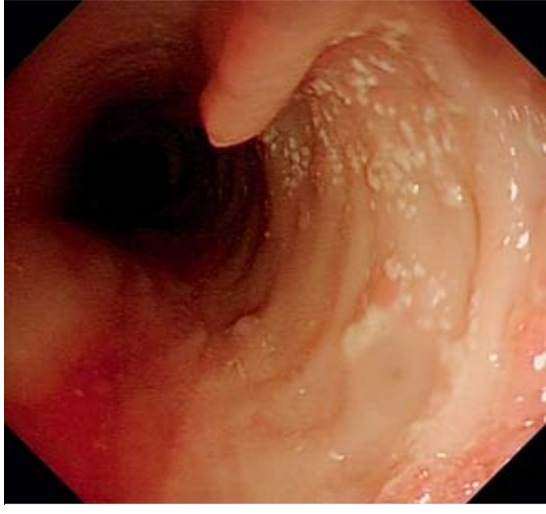

- Fig. 3 Follow-up endoscopy 4 weeks after showing complete resolution of the septum.

\section{ENDOSCOPY E-VIDEOS}

https://eref.thieme.de/e-videos

回回 Endoscopy E-Videos is a free access online section, reporting an: on interesting cases and new techniques in gastroenterological endoscopy. All papers include a high quality video and all contributions are freely accessible online.

This section has its own submission website at

https://mc.manuscriptcentral.com/e-videos 